\title{
Orbital Epithelial Implantation Cyst Presenting 40 Years after Orbital Trauma*
}

\author{
Saruban Pasu ${ }^{1}$, Partha Chakraborty ${ }^{2 \#}$ \\ ${ }^{1}$ Moorfields Eye Hospital, London, UK; ${ }^{2}$ Darlington Memorial Hospital, Durham, UK. \\ Email: "pceye@yahoo.co.uk
}

Received January $20^{\text {th }}, 2013$; revised March $15^{\text {th }}, 2013$; accepted April 26 ${ }^{\text {th }}, 2013$

Copyright (C 2013 Saruban Pasu, Partha Chakraborty. This is an open access article distributed under the Creative Commons Attribution License, which permits unrestricted use, distribution, and reproduction in any medium, provided the original work is properly cited.

\begin{abstract}
Here we present an unusual case of an epithelial implantation cyst within the orbit which presented 40 years after initial injury from an airgun pellet. A retrospective review of the case will be performed. This case is to highlight the importance of taking a thorough history when assessing adnexal lesions of undetermined origin.
\end{abstract}

Keywords: Orbital Epithelial Implantation Cyst

\section{Case}

A 69-year-old Caucasian man presented with a two week history of diplopia on upgaze and right upper lid swelling. His only history of note was of an airgun injury to his right orbit 40 years ago which required surgical removal of the pellet.

His corrected Snellen visual acuity was 6/5 bilaterally. There was a right superomedial orbital swelling not involving the eyelid margins (Figure 1). There was no manifest squint in the primary position. Limitation of right upgaze was noted. Anterior and posterior segments of both eyes were normal with no proptosis. Intraocular pressures were $16 \mathrm{mmHg}$ bilaterally.

Magnetic resonance imaging (Figures 2 and 3) showed a non enhancing soft tissue lesion in the anterior superior quadrant, $26 \mathrm{~mm}$ in maximum dimension. The mass was extraconal and displaced the right globe laterally. Anteriorly it was indistinguishable from the subcutaneous tissue and appeared to be intimately related to the inferior aspect of superior oblique. It demonstrated high signal characteristics on $\mathrm{T} 1$ and low signal on $\mathrm{T} 2$.

A chest $\mathrm{x}$-ray and routine haematological investigations were normal.

An explorative excision biopsy was undertaken. Histological analysis confirmed keratinising squamous epithelium, and flattened double-layered epithelium which

\footnotetext{
*The authors declare that they have no proprietary interests related to this article.

No financial support was necessary.

${ }^{\#}$ Corresponding author.
}

had no specific distinguishing features. There were no skin appendage structures suggestive of a dermoid. These features are consistent with a diagnosis of an epithelial implantation cyst arising from orbital trauma 40 years previously.

\section{Discussion}

This case highlights the problems with diagnosing adnexal lumps. A nasolacrimal apparatus lesion was considered in our differential but no involvement of the nasolacrimal system was found on surgical exploration. Similarly imaging showed no sinus involvement, thus excluding a mucocoele as a potential diagnosis.

Epithelial implantation cysts are a rare complication of orbital surgery or trauma. These cysts are epithelial lined

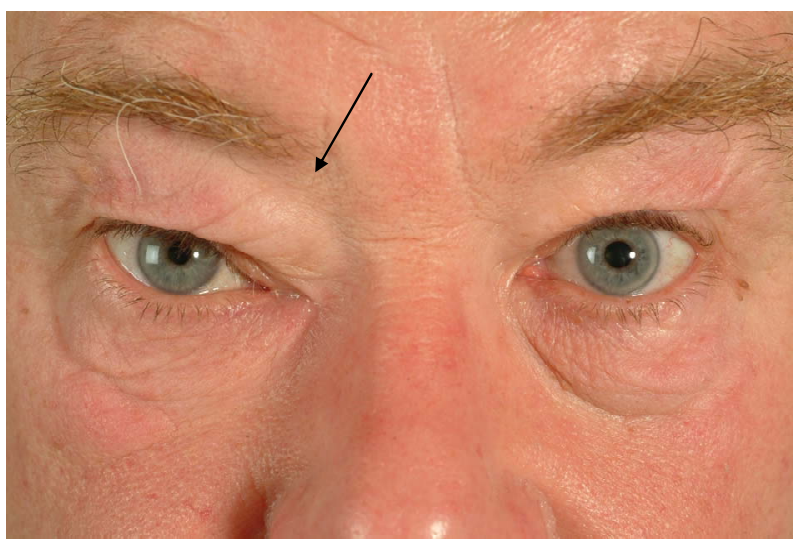

Figure 1. Photograph showing right orbital swelling. 


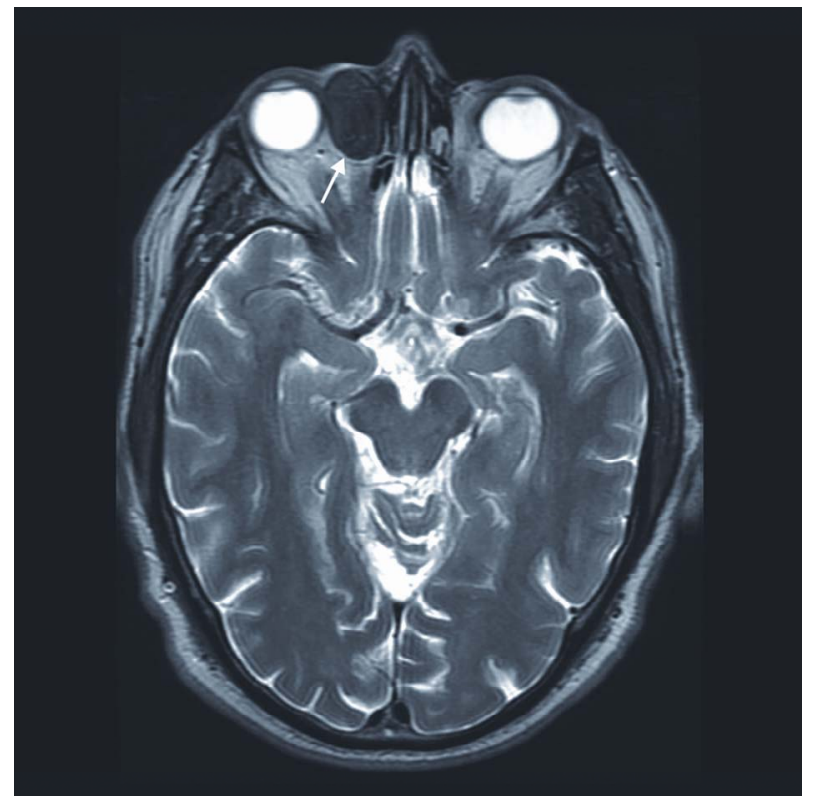

Figure 2. Pre op MRI axial view showing cyst in right orbit.

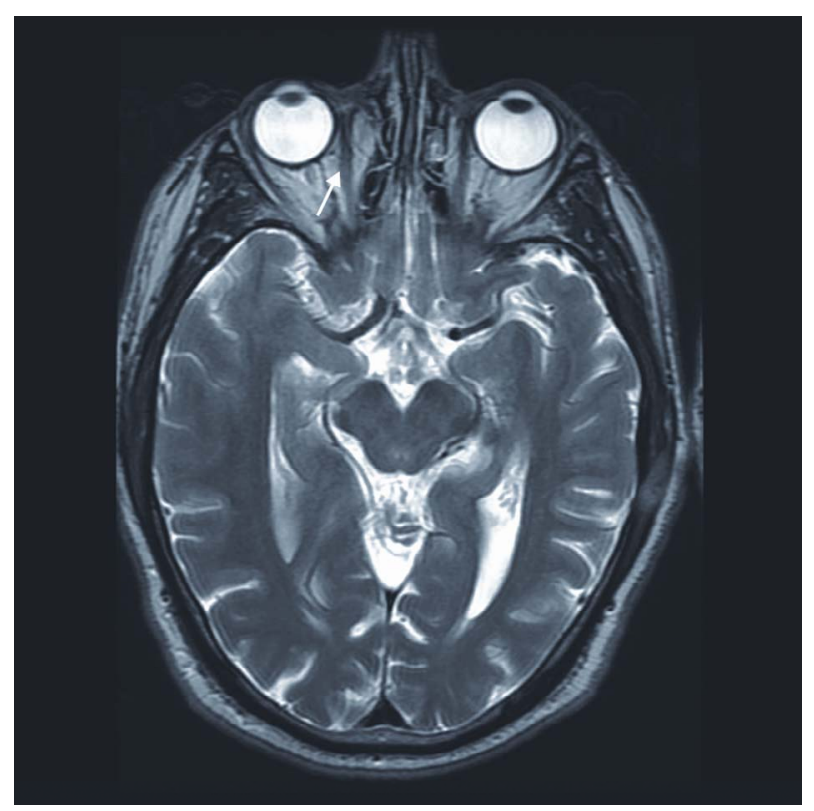

Figure 3. Post op MRI brain and orbits. Axial view showing clearance of cyst.

structures found within the subcutaneous tissues or deeper structures and are separated from the normal epithelium. They arise secondary to delivery of epithelial cells to deeper areas following tissue manipulation.

Epithelial implantation cysts after squint surgery are a rare but recognised late complication which can present decades after the initial surgery [1]. The precise incidence of cyst formation after surgery is unknown and it is likely that formation after surgery is site and surgeons specific. Wuebbolt and colleagues [2] reported two epithelial implantations cysts of conjunctival origin from 109 upper eyelid-lowering procedures suggesting the incidence may be higher than previously thought.

Presentation with implantation cysts can occur several decades following elective surgery. Song et al. [1] reported 4 cases of giant conjunctival cysts after surgical squint correction, one of which presented 46 years postoperatively. Jünemann and Holbach [3] presented the case of a 54-year-old who was diagnosed with a conjunctival epithelial cyst following enucleation without orbital implant 50 years after surgery. Our review of the literature suggested that cases secondary to trauma may appear quicker with the longest latent periods reported being 15 years [4] and 24 years following trauma [5].

The risk factors for development of implantation cysts are unknown. We hypothesise that trauma is more likely to give rise to cyst formation than elective surgery. As in our case, we believe that injuries in which a foreign material has been embedded in deeper tissues are more likely to carry epithelial cells to deeper layers. Surgical technique in debriding and closing of these wound is also likely to play a role in development of cysts.

Our case is the first to report epithelial cyst formation following an airgun pellet injury. It is apparent that obtaining a thorough history of childhood surgery and trauma is vital in diagnosing adenexal lesions.

We would like to acknowledge Dr. Alan Cunningham MBBS FHEA for his support.

\section{REFERENCES}

[1] J. J. Song, P. T. Finger, M. Kurli, H. J. Wisnicki and C. E. Iacob, "Giant Secondary Conjunctival Inclusion Cysts: Late Complication of Strabismus Surgery,” Ophthalmology, Vol. 113, No. 6, 2006, pp. e1-e2.

[2] G. E. Wuebbolt, M. Zuercher, B. O’Donnell and R. Collin, "Epithelial Implantation Cysts of the Upper Eyelid after Lid-Lowering Procedures,” Ophthalmology, Vol. 100, No. 9, 1993, pp. 1289-1292.

[3] A. Jünemann and L. M. Holbach, "Epithelial Giant Inclusion Cyst 50 Years after Enucleation without Orbital Implant,” Klinische Monatsblatter fur Augenheilkunde, Vol. 212, No. 2, 1998, pp. 127-128. doi:10.1055/s-2008-1034848

[4] E. Alexandridis, H. Weidauer, V. Seiberth and W. Daus, "Large Orbital Cyst after Injury,” Orbit, Vol. 7, No. 1 1988, pp. 67-70. doi:10.3109/01676838809036129

[5] A. Miyagi, K. Maeda and T. Sugawara, "Intraorbital Conjunctival Cyst after a Penetrating Orbital Injury: A Case Report,” No Shinkei Geka, Vol. 24, No. 7, 1996, pp. 649653. 